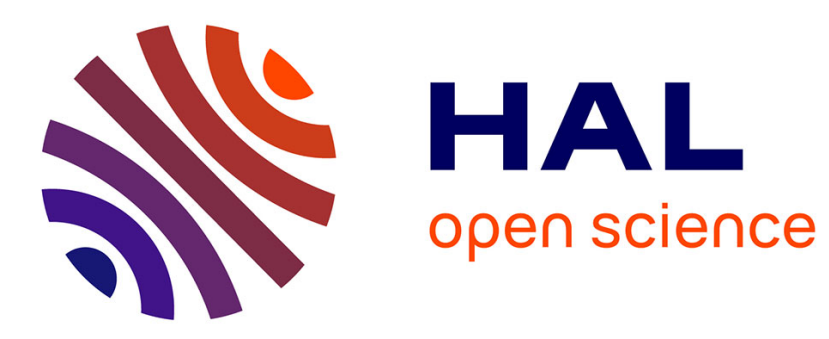

\title{
Homocysteine and stroke: another brick in the wall
}

Simona Sacco, Antonio Carolei

\section{To cite this version:}

Simona Sacco, Antonio Carolei. Homocysteine and stroke: another brick in the wall. Clinical Science, 2009, 118 (3), pp.183-185. 10.1042/CS20090371 . hal-00529571

\section{HAL Id: hal-00529571 \\ https://hal.science/hal-00529571}

Submitted on 26 Oct 2010

HAL is a multi-disciplinary open access archive for the deposit and dissemination of scientific research documents, whether they are published or not. The documents may come from teaching and research institutions in France or abroad, or from public or private research centers.
L'archive ouverte pluridisciplinaire HAL, est destinée au dépôt et à la diffusion de documents scientifiques de niveau recherche, publiés ou non, émanant des établissements d'enseignement et de recherche français ou étrangers, des laboratoires publics ou privés. 


\section{HOMOCYSTEINE AND STROKE: ANOTHER BRICK IN THE WALL}

Simona Sacco and Antonio Carolei

Clinica Neurologica, Università degli Studi di L'Aquila

Correspondence to: prof. Antonio Carolei, Clinica Neurologica, Università degli Studi di L'Aquila, Piazzale Salvatore Tommasi 1, 67010 L'Aquila, Italy; tel. and fax: +39.0862.64153; e-mail: a_carolei@yahoo.com

\section{Abstract}

After a long debate, due to conflicting data from clinical studies, homocysteine is now largely accepted as a risk factor for cardiovascular diseases including stroke. To date, the role of elevated homocysteine values in stroke recurrences has not been evaluated and consequently we acknowledge the paper by zhang et al that proves that patients with high homocysteine values have an increased risk for stroke recurrence and for all-cause mortality with respect to patients with lower values. Remarkably, in their study high homocysteine values were associated with an increased risk of stroke recurrence and of all-cause mortality in patients included for an atherothrombotic stroke and an intracerebral hemorrhage but not in patients who were included for a lacunar stroke. The study by Zhang et al., gives important information for clinical practice and represents the basis for further investigations since it raises questions referring to the puzzling relationship between homocysteine and cardiovascular disease. Moreover, results support the hypothesis that, for undisclosed reasons, the relationship between homocysteine and cardiovascular disease may not be homogeneous for all the conditions encompassed in the category of cardiovascular disease, being peculiar for stroke patients. The finding of an association between high homocysteine values and risk of recurrent stroke or all-cause mortality in patients with intracerebral hemorrhage should be taken with caution until this same result will be confirmed in other case-series with different ethnicity.

\section{Key-words}

stroke, intracerebral hemorrhage, homocysteine, mortality, atherothrombosis 
After a long debate, due to conflicting data from clinical studies, homocysteine is now largely accepted as a risk factor for cardiovascular diseases including stroke. [1] The mechanism through which homocysteine promotes cardiovascular disease is mostly related to its capacity to be a causative agent for atherosclerosis through endothelial injury, platelet activation, smooth muscle proliferation, oxidative modification of low-density lipoproteins, and endothelial-leukocyte interactions. [2] To date, the role of elevated homocysteine values in stroke recurrences has not been evaluated and consequently we acknowledge the paper by zhang et al., aimed to assess the relationship between homocysteine and secondary vascular events or death in patients with stroke.[3] In the 2,000 patients with atherothrombotic stroke, lacunar infarction, or intracerebral hemorrhage included in the Multicenter Chinese stroke study, authors found that after adjustment for age, sex, and conventional vascular risk factors, patients in the highest quartile of plasma homocysteine concentration $(\geq 19.8 \mu \mathrm{mol} / \mathrm{L})$ had an increased risk of 1.74fold for stroke recurrence (relative risk [RR] 1.74, 95\% CI 1.3-2.3; $\mathrm{P}$ for trend $<0.0001$ ) and 1.75-fold for all-cause mortality ( $R R$ 1.75, 95\% CI 1.3-2.4; $\mathrm{P}$ for trend <0.0001) with respect to patients in the lowest quartile $(<11.5$ umol/L). Particularly, the increased risk in mortality was mostly due to a positive association with cardiovascular death ( $R R$ 1.88, 95\% CI 1.2-2.7; $P$ for trend=0.006) since the risk of non-cardiovascular death ( $R R$ 1.14, 95\% CI 0.71.9; P for trend=0.59) was not increased. Remarkably, when referring to specific subgroups they found that high homocysteine values were associated with an increased risk of stroke recurrence and of all-cause mortality in patients included for an atherothrombotic stroke and an intracerebral hemorrhage but not in patients who were included for a lacunar stroke. This result is in agreement with data showing that in patients with stroke, increasing plasma homocysteine values were associated with ischemic stroke caused by large-artery atherosclerosis and, to a much lesser extent, by small-artery disease, but not cardioembolic or other etiologic subtypes of ischemic stroke.[4] Intriguingly, in the study by zhang et al. the MTHFR variant $\mathrm{C} 677 \mathrm{~T}$ was not associated with a greater risk for stroke recurrence and all-cause mortality.

The study by Zhang et al., gives important information for clinical practice and represents the basis for further investigations since it raises questions referring to the puzzling relationship between homocysteine and cardiovascular disease. Several interventional prospective studies have demonstrated that administration of folate and 
vitamin $B_{12}$ lowers plasma homocysteine levels $[5,6]$ but clinical trials failed to demonstrate any benefit from homocysteine-lowering therapy on secondary prevention of cardiovascular disease [7-11] making questionable any evidence in support of a possible reduction in cardiovascular risk through a reduction in homocysteine values. Several interpretations were taken into account to explain the negative results of the trials [including] as [that] mild hyperhomocysteinemia may not represent a causative risk factor, that the statistical power of the trials was insufficient to exclude a small clinical benefit, that homocysteine-lowering therapy with combinations of $B$ vitamins produces some adverse vascular effects that mask the benefit of lowered homocysteine values, that the duration of the trials was too short, or that mild hyperhomocysteinemia is associated with an increased vascular risk not because it is directly involved in the pathogenesis of vascular disease but because it is a marker of other harmful processes such as chronic kidney disease. Moreover, given our knowledge of the mechanisms of action of homocysteine, we can not exclude that the effects of elevated homocysteine values on the brain might be irreversible.[12] If this is the case, once the pathological changes have appeared, the beneficial effects of vitamin supplementation would be limited. Consequently, trials to evaluate this possibility should examine the impact of $B$ vitamin supplementation in the primary prevention of cardiovascular disease, especially giving treatment at an earlier point in the development of atherosclerosis while the available trials evaluated the role of homocysteine in patients who already presented cardiovascular disease. Moreover, results from the study by Zhang et al. support the hypothesis that, for undisclosed reasons, the relationship between homocysteine and cardiovascular disease may not be homogeneous for all the conditions encompassed in the category of cardiovascular disease, being peculiar for stroke patients. In fact, in the Heart Outcomes Prevention Evaluation 2 (HOPE-2) study, despite homocysteine-lowering B vitamin therapy was not better than placebo in terms of the primary composite outcome of cardiovascular death, myocardial infarction, and stroke, the risk of stroke was reduced by 25\%. [10] Similarly, a post-hoc analysis of data from the Vitamin Intervention for Stroke Prevention (VISP) trial excluding patients likely to have $B_{12}$ malabsorption, who were taking $\mathrm{B}_{12}$ supplements outside the study, and patients with renal impairment showed that high-dose vitamin therapy significantly reduced stroke, coronary events, and death. [13] For the above reported reasons, at present there 
are insufficient data to reliably exclude a clinically important effect of $B$ vitamins in preventing stroke, especially according to patient subgroups and stroke types. Studies evaluating the role of homocysteine lowering treatment in primary and secondary stroke prevention focusing particularly on subtypes of ischemic stroke are warranted.

At last, a comment should be given to the reported association between high homocysteine values and risk of recurrent stroke or all-cause mortality in patients with intracerebral hemorrhage. This finding replicates what the authors already reported in the same cohort of patients $[14,15]$ and can not be easily explained. We think that before going through mechanisms that might explain the reported association the same should be confirmed in other case-series with different ethnicity in order to disclose whether race is the main determinant of such an association. 


\section{References}

1. Wald, D.S., Law, M. and Morris, J.K. (2004) Homocysteine and cardiovascular disease: evidence on causality from a meta-analysis. BMJ 325, 1202

2. Thambyrajah, J. and Townend, J.N. (2000) Homocysteine and atherothrombosis-mechanisms for injury. Eur. Heart J. 21, 967-974

3. Zhang, W., Sun, K., Chen, J., Liao, Y., Qin, Q., Ma, A., Wang, D., Zhu, Z., Wang, Y. and Hui, R. (2009) High plasma homocysteine levels contribute to the risk of stroke recurrence and all-cause mortality in a large prospective stroke population. Clin. Sci. (Lond.) 00, 000-000

4. Eikelboom, J.W., Hankey, G.J., Anand, S.S., Lofthouse, E., Staples, N. and Baker, R.I. (2000) Association between high homocyst(e)ine and ischemic stroke due to large- and small-artery disease but not other etiologic subtypes of ischemic stroke. Stroke 31, 1069-1075

5. Ranganath, L.R., Baines, M. and Roberts, N.B. (2001) Homocysteine and thiol metabolites in vitamin B12 deficiency. Clin. Sci. (Lond.) 100, 111-116

6. Stam, F., Smulders, Y.M., van Guldener, C., Jakobs, C., Stehouwer, C.D. and de Meer, K (2005) Folic acid treatment increases homocysteine remethylation and methionine transmethylation in healthy subjects. Clin. Sci. (Lond.) $108,449-456$

7. Bazzano, L.A., Reynolds, K., Holder, K.N. and He, J (2006) Effect of folic acid supplementation on risk of cardiovascular diseases: a meta-analysis of randomized controlled trials. JAMA 296, 2720-2726

8. Bønaa, K.H., Njolstad, I., Ueland, P.M., Schirmer, H., Tverdal, A., Steigen, T., Wang, H., Nordrehaug, J.E., Arnesen, E. and Rasmussen, K. (2006) Homocysteine lowering and cardiovascular events after acute myocardial infarction. N. Engl. J. Med. 354, 1578-1588

9. Jamison, R.L., Hartigan, P., Kaufman, J.S., Goldfarb, D.S., Warren, S.R., Guarino, P.D. and Gaziano, J.M. for the Veterans Affairs Site Investigators (2007) Effect of homocysteine lowering on mortality and vascular disease in advanced chronic kidney disease and end-stage renal disease: a randomized controlled trial. JAMA 298, 1163-1170 
10. Lonn, E., Yusuf, S., Arnold, M.J., Sheridan, P., Pogue, J., Micks, M., McQueen, M.J., Probstfield, J., Fodor, G., Held, C. and Genest, J. (2006) Homocysteine lowering with folic acid and B vitamins in vascular disease. N. Engl. J. Med. 354, 1567-1577

11. Toole, J.F., Malinow, M.R., Chambless, L.E., Spence, J.D., Pettigrew, L.C., Howard, V.J., Sides, E.G., Wang, C.H. and Stampfer, M. (2004) Lowering homocysteine in patients with ischemic stroke to prevent recurrent stroke, myocardial infarction, and death: The vitamin intervention for stroke prevention (VISP) randomized controlled trial. JAMA 291, 565-575

12. Sacco, S. and Carolei, A. (2007) Homocysteine and leukoaraiosis: time for a clinical trial? Neurol. Sci. 28, 235-237.

13. Spence, J.D., Bang, H., Chambless, L.E. and Stampfer, M.J. (2005) Vitamin intervention for stroke prevention trial: an efficacy analysis. Stroke 36, 2404-2409

14. Li, Z., Sun, L., Zhang, H., Liao, Y., Wang, D., Zhao, B., Zhu, Z., Zhao, J., Ma, A., Han, Y., Wang, Y., Shi, Y., Ye, J. and Hui, R.; Multicenter Case-Control Study in China. (2003) Elevated plasma homocysteine was associated with hemorrhagic and ischemic stroke, but methylenetetrahydrofolate reductase gene $\mathrm{C} 677 \mathrm{~T}$ polymorphism was a risk factor for thrombotic stroke: a Multicenter Case-Control Study in China. Stroke 34, 2085-2090

15 Xue, H., Wang, H. Song, X., Li, W., Sun, K., Zhang, W., Wang, X., Wang, Y. and Hui, R. (2009) Phosphodiesterase 4D gene polymorphism is associated with ischaemic and haemorrhagic stroke. Clin. Sci. (Lond.) 116, 335-340 